\title{
L'imaginari popular en sant Vicent Ferrer: semblances $i$ exemples en els Sermons vicentins
}

\author{
[The folk imaginary in Saint Vincent Ferrer: similarities and \\ examples in the Vicentine Sermons]
}

\author{
JOAN BORJA I SANZ \\ Universitat d'Alacant \\ joan.borja@ua.es
}

\begin{abstract}
Resum: Els Sermons de sant Vicent Ferrer constitueixen un veritable tresor des del punt de vista lingüístic, i —òbviament— també des d'una òptica teològica. En aquesta aportació, tanmateix, es proposa una aproximació analítica als Sermons de Vicent Ferrer des de perspectives etnopoètiques: atenent relats, motius, temes, creences, arguments, imatges i referents narratius directament manllevats pel dominic valencià a l'imaginari popular del seu temps. L'estudi de les semblances i els exemples inserits en els Sermons vicentins no solament aporta llum sobre les tècniques comunicatives i les estratègies discursives de la predicació vicentina, sinó també sobre alguns aspectes concrets —etnopoèticament interessantíssimsdel patrimoni rondallístic valencià. Així, per exemple, resulta que algunes narracions internacionalment indexades i tipificades, que durant els dos últims segles mai no han pogut ser identificades i catalogades dins de l'àmbit cultural valencià, sí que poden ser documentades, en canvi, en els Sermons de sant Vicent. Aquest és el cas, sense anar més lluny, del tipus ATU 1 («The Theft of Fish»), i també del tipus ATU 1331 («The Covetous and the Envious»).
\end{abstract}

Paraules ClaU: sant Vicent Ferrer, etnopoètica, predicació, sermons, rondalles, ATU 1, ATU 1331

Aвstract: The Sermons of Saint Vincent Ferrer are a true treasure from a linguistic point of view, and, obviously, from a theological position. In this contribution, however, an analytical approach to the Sermons of Vincent Ferrer is proposed from several ethnopoetic perspectives: taking into account narrative motifs, themes, beliefs, arguments, images and referents, directly borrowed from the folk imaginary. The study of the similarities and examples inserted by Saint Vincent Ferrer not only brings light on the communicative techniques and the discursive strategies of his preaching, but also on some specific features - very interesting etnopoetically — about Valencian folktales. So, for example, some internationally indexed and typified folktales, which have never been identified nor catalogued in the Valencian cultural context for the last two centuries, can be documented, however, in the Sermons of Saint Vincent Ferrer. This is the case, without going any further, of type ATU 1 («The Theft of Fish»), and also of type ATU 1331 («The Covetous and the Envious»).

KEYWORDs: Saint Vincent Ferrer, ethnopoetics, preaching, sermons, folktales, ATU 1, ATU 1331

Recepció: 26/02/2019. Acceptació: 08/03/2019. Publicació: 05/04/2019

REVISTA VALENCIANA DE FILOLOGIA/III (2OI9) p. 5I-76 / ISSN 0556-705X / DOI I0.28939/RVF.V3IO.59 
Els Sermons de sant Vicent Ferrer, com bé indica Gret Schib en l' 'Advertiment» preliminar al tercer volum de l'edició d' «Els Nostres Clàssics», mereixen ser destacats en la història cultural valenciana per la «importància, prou coneguda, d'aquest text que ultrapassa els límits de la literatura i ens ofereix un panorama de la vida de la primeria del segle Xv. A més, és un testimoni viu de la llengua popular d'aquella època» (SСHib 1975: 7). En efecte: els Sermons vicentins constitueixen un veritable tresor des del punt de vista lingüístic, i han estat degudament estimats per la filologia, tant en l'àmbit de l'estudi de la variació lingüística com en la història de la literatura, així com també — no cal dir-hodes d'una òptica teològica, en l'àmbit de la història del cristianisme.

La transcripció de la paraula oral i viva del dominic valencià per part dels reportadors (admiradors de la figura del sant, que devien formar part del seguici que l'acompanyava en els llargs, constants i infatigables viatges), ens procura la privilegiada oportunitat d'obtenir una idea aproximada, sis segles després, sobre les característiques de la predicació vicentina. Però no solament això: també, i més generalment —com apuntava Schib—, «un panorama de la vida de la primeria del segle Xv». En aquest panorama s'inclouen també relats, motius, temes, llocs comuns, arguments i referents narratius propis de la literatura oral, directament manllevats a l'imaginari popular del moment. Per això, els Sermons de Vicent Ferrer, a més dels ja suggerits interessos per a l'estudi lingüístic, literari o teològic, ofereixen també un valuosíssim interés per a etnopoètica diacrònica.

El dominic Vicent Ferrer va ser un predicador d'èxit: un dels més escoltats i venerats del seu temps - i, segurament, de tots els temps. La fama el precedia allà on anava- El seu ben bé podia ser considerat un fenomen de masses equiparable, salvant totes les distàncies, a la dels grups musicals o cantants de més èxit —i amb més quantitat de fans- en l'actualitat. Així ho acredita, per exemple, l'anècdota que se li atribueix en relació amb la predicació al convent de Sant Domènec de Palma, l'any 1413, en què la previsió d'afluència de feligresos va fer prendre una decisió dràstica: l'enderrocament de la paret de l'hort

REVISTA VALENCIANA DE FILOLOGIA / I I I (20I9) p. 5I-76 JOAN BORJA I SANZ

L'imaginari popular en sant Vicent Ferrer: semblances $i$ exemples en els Sermons vicentins / 52 
que circumdava el convent per tal de guanyar espai — capacitat d'aforamentper a la multitud que s'hi esperava. Així ho recorda, per exemple, la Historia de la vida, milagros, muerte y discípulos del Bienaventurado predicador apostólico valenciano S. Vicente Ferrer de la Orden de Predicadores, de l'any 1600:

El concurso de la gente que acudía a oyr los sermones del Santo era tal que con ser verdad que la Iglesia del convento es grandísima, con todo eso se huvo de poner por tierra una pared del huerto del monasterio para que predicando y diziendo misa en un gran tablado que en él se hizo pudiese ser visto de todos.

Els sermons de sant Vicent devien exhibir una força verbal i una posada en escena absolutament espectaculars, que es traduïen en una enorme capacitat persuasiva per a l'evangelització, la conversió, el penediment i la contrició de les multituds. Una de les astúcies discursives que sens dubte devien contribuir estratègicament a aquesta capacitat d'empatia i d'emotivitat per part dels assistents a les predicacions era l'hàbil incursió d'elements literaris populars, del gust del públic. Aquest públic els devia reconéixer afectivament. I hi operaven efectivament com semblances o exemples morals, d'una manera semblant a les paràboles bíbliques. El mateix Vicent Ferrer explicitava la importància que, per a ell, aquest exemples tenien per a la construcció dels sermons, al costat de l'argumentació i la interposició d'autoritats:

La preycació [...] és comparada al filat, que hun fil és lligat ab altre, e quan ve que tiren a ssi lo filat, tot lo filat segueix; axí la preycació deu ésser lligada, I exemple ab altre, una autoritat ab altra, depuix ab lo fil tire hom lo filat; axí, ab lo tema, tire hom tot lo sermó si bé és ordenat (Ferrer 1410: II, 46).

Les semblances i els exemples, així doncs, constitueixen, en la prosa religiosa de sant Vicent Ferrer, una mena de saboritzant que aporta amenitat i sapidesa als preceptes, les admonicions, les explicacions i els arguments. Sanchis Guarner, per això, quan es refereix als «apòlegs i paràboles dels sermons

REVISTA VALENCIANA DE FILOLOGIA / I I I (20I9) p. 5I-76 JOAN BORJA I SANZ L'imaginari popular en sant Vicent Ferrer: semblances $i$ exemples en els Sermons vicentins / 53 
vicentins", no s'està de modalitzar el propi discurs per a indicar que els troba «deliciosos»:

De fet, aqueixos apòlegs i paràboles dels sermons vicentins —que nosaltres trobem tan deliciosos- eren rònegament esquemes vius d'una veritat abstracta, la qual el predicador, per tal de fer-la entenedora i assimilable per la massa popular, presentava inserida en anècdotes reals o fictícies. (SANCHIS 1973: 24)

Per als ulls del lector actual, de més a més, aquests elements narratius de les predicacions vicentines tenen el valor de constituir una mena de finestra oberta per a albirar, salvant una distància de més de sis segles, un determinat repertori de narracions populars medievals, no sempre de temàtica estrictament religiosa. Es tracta de relats i motius argumentals que ben podem suposar d'autoria anònima, coneixement generalitzat i transmissió oral. És a dir: materials literaris que configuren, ben mirat, un atractiu objecte d'estudi per a l'etnopoètica.

Pot servir, com a primera mostra d'aquesta vinculació dels sermons vicentins amb la narrativa popular de l'edat mitjana, l'exemple dels dos homes deutors del rei. Es tracta d'un relat molt senzill, que reconta el cas de dos homes empresonat per haver contret amb el rei un deute econòmic tan important que de cap de les maneres no el podrien assumir. Tenien, aquests deutor, perill de perdre la vida, si el rei no hi volia mostrar-se pietós. Tanmateix, el monarca decideix oferir-los una immillorable oportunitat per a saldar el deute i guanyar la llibertat. Però no tots dos sabran aprofitar-la de la mateixa manera, l'oportunitat en qüestió:

E ací vos diré hun bell exemple. Sapiau que una vegada eren dos hòmens, e cascú de aquells devie al rey mil florins, e eren axí pobres, que no·n havie cascú.X florins per a pagar; e veus que·l rey los dix que pagassen. «Senyor, no havem, de què». «No, yo vull ésser pagat». E feu-los pendre e metre en una presó. E veus que, quan vench a cap de alguns dies, lo rey, perquè ere tan misericordiós, hac-ne pietat, dient: «Oo, tots temps porien estar allí, certes; yo los vull perdonar. Mas, per tal com yo he dit que vull ésser pagat,

REVISTA VALENCIANA DE FILOLOGIA / I I I (20I9) p. 5I-76

JOAN BORJA I SANZ

L'imaginari popular en sant Vicent Ferrer: semblances $i$ exemples en els Sermons vicentins / 54 
faré així: faré lançar mil florins en la presó de cascú, e puix exiran, e pagar m'an». E així·u feu. Ell appellà son tresorer e manà-li que anàs de nit a la presó de aquells dos hòmens, e que bé not (?) que degú no·u sentís, que lançàs en un bossot mil florins en la presó de cascú. E aquell, tantost que vench lo vespre, ell se n'anà a la presó de la hu, e gint gint, per la finestra, lançà los mil florins en la hu, e anà-sse'n; e, així com los florins entraren, ell dormie davant la fenestra, e donaren-li en lo cap, e trencaren-lo-li, e aquell, tot irat, veus que·s lleva. «Oo, mesquí! Demà me han a pengar e encara me han trenquat lo cap». Tost, tost, ell cerque ab què ho havien feyt, e trobà·u, e no guardà que·y havie, e anà-sse'n a la fenestra, e rebatél, e lançà'l de fora. E, aquell que-ls li havia lançats, pren-los e va-sse'n a la presó del altre, e així mateix lançà-li altres mil florins per la fenestra, e donaren-li en lo braç, e trenquaren-lo-li; e aquell, veus que no pogué rebatre lo colp, mas anà e guardà què ere. Així com ho veu, de lluny dix: "Açò par que sia bossa; cert, sí he». E obrí-la e trobà·y sos mil florins. «Oo, tan bon dia, ara poré pagar al rey, e escaparé de mort. Oo, Senyor! Gràcies te sien feytes. O, tan bon trenquar de braç és estat aquest!». E veus que, quan vench en l'endemà, lo rey los se feu venir davant. "Ara pagau-me». E tantost aquell del braç trenquat, dix: «Veus ací mil florins», e escapà de mort. E l'altre dix: «Senyor, sapiau que anit qualque ribaud vench a la presó, e per la fenestra lançà'm una cosa dura, e trenquà'm lo cap, e fuy irat e vayg-la-li rebatre, e no tinch de què pagar». "O traydor! $\mathrm{E}$, donchs, los mil florins has lançats?» «O, senyor, no-u sabia». «Qui la fa, la follia, que la-s bega; tost, tost, pengau-lo», e tantost fo pengat. vet; si no hagués rebatut lo colp, no fore mort (FERRER 1410: I, 250-251).

La fàcil i evident identificació entre la figura de Déu i la d'un rei o la d'un senyor feudal habilita, en els sermons de Vicent Ferrer — com en aquesta primera narració transcrita, dels dos deutors empresonats-, l'oportunitat d'incloure tot un repertori de relats protagonitzats per figures monàrquiques, nobiliàries $\mathrm{o}$ senyorials amb oportunitat de posar a prova (i jutjar!) els caràcters, les actituds i les accions dels súbdits.

Segurament, un dels relats més colpidors d'aquest repertori és el conegut exemple de l'envejós i l'avariciós, que davant l'oferta del rei de concedir-los

REVISTA VALENCIANA DE FILOLOGIA / I I I (20I9) p. 5I-76

JOAN BORJA I SANZ

L'imaginari popular en sant Vicent Ferrer: semblances $i$ exemples en els Sermons vicentins / 55 
una voluntat en agraïment pels serveis prestats al seu dia pels respectius pares, reaccionen d'una manera absolutament imprevista i sorprenent. I és que la concessió del desig per part del rei té també una curiosa condició: que allò que vulga demanar el primer dels protagonistes, serà concedit de manera doble al segon. Per això, evidentment, l'envejós i l'avariciós se cediran emfàticament, amb impostada cortesia, l'honor que siga l'altre el primer a formular la petició. Fins que el rei, per resoldre la situació, decidirà que siga un —l'envejós, precisament- el primer a triar. I aquest demanarà el més pèrfid i impensat dels desitjos:

En una ciutat havia dos hòmens de gran honor; la hu era molt envejós, e l'altre fort avariciós, e la fama era per tota la ciutat. E veus que hun dia lo rey o sabé, e dix: "¿Voleu que pach yo aquests dos hòmens?» «Hoc, senyor». Veus que ell los appellà, e, quan foren davant ell, lo rey los dix: "Ara veus, honrats hòmens: vostres pares me han feta molta de honor $\mathrm{e}$ servir, e per ço que·ls altres me vullen millor servir, yo vos vull guardonar de aquell serví; e així, demanau ço que vullau, que yo vos promet de donarvos-ho, e lo qui demanarà derrer yo li promet de dar-lo-li en doble, qui si la hu demane una ciutat, l'altre ne haurà dues». E veus que ells estan qual dirà: «Digau vos, que sou major». "Mas vos, que sou de major llinatge». E així ells se contenien, e no volien dir, e lo rey dix: «Sus, demanau. Ara voleu que·u diga yo qual demanarà primer?" «Hoc, senyor». "Donchs, sus, vos, al envejós, demanau primer». E aquell està pensant: si yo deman hun cavall, aquell ne haurà dos; si deman una vila, aquell ne haurà dues. «Senyore, ¿confermau de dar-li lo doble a aquell?». «Hoc». «Ara, yo vos deman aquesta gràcia: que.m tragau la hun huyll». «Bé·m plau». E quan lo·y trahien: «Hoc, mas a aquell dos». E així fo, e·u legim. Ara guarda, donchs, com enveja guasta si mateix e·ls altres. Ideo dicet Scriptura: «Vita

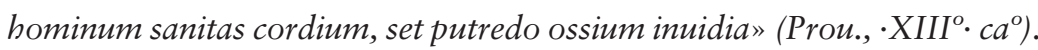

Lo envejós no ha bé, ni qui de prop lo té (Ferrer 1410: I, 224-225).

Aquest relat de l'avar i l'envejós no és sinó un tipus ben conegut internacionalment: "The Covetous and the Envious», catalogat com a ATU 1331 en The Types of International Folktales, amb l'esquema argumental següent: «God (angel, saint, ruler) tries to reconcile a covetous man and an envious one

REVISTA VALENCIANA DE FILOLOGIA / I I I (20I9) p. 5I-76 JOAN BORJA I SANZ

L'imaginari popular en sant Vicent Ferrer: semblances i exemples en els Sermons vicentins / 56 
(two hostile neighbors): Whatever one of them wishes, the other shall receive double. The covetous one, hoping to get the double price, gives the envious one opportunity to wish first. The envious one wants to have one of his eyes removed». ${ }^{1}$ Es tracta, en qualsevol cas, d'un tipus de narració popular que ja apareixia en els faules de Flavius Avianus, i que ha fet tanta fortuna universal que en el segle XIX o Xx s'ha pogut documentar en reculls rondallístics letons, lituans, francesos, portuguesos, frisons, flamencs, alemanys, italians, maltesos, hongaresos, txecs, macedonis, búlgars, grecs, jueus, armenis, iranians, pakistanesos, indis, birmans, australians i nord-americans. ${ }^{2}$

La condició humana s'hi pot manifestar així: podent triar el bé o la riquesa que es vulga, el personatge envejós del relat vicentí —un relat universal, al cap i a la fi- es demostra incapaç de suportar la idea que el veí hi puga obtenir el doble de fortuna, i per això s'estima més que li traguen un ull: pel pur, insolidari i sàdic plaer de saber que al rival li hauran de traure els dos. «Lo

1 Vegeu Hans-Jörg Uther (2011, II, 130). Es tracta d'un tipus semblant al 750A, també molt conegut, en què Nostre Senyor és acollit caritativament i concedeix a l'amo de la casa tres desitjos. L'home demana trobar un cullerot que ha perdut. La muller, que pensa que calia demanar riqueses, diu indignada que tant de bo se li quedi enganxat al nas. I el tercer desig, per tant, ha de ser, necessàriament, desenganxar el cullerot del nas del marit. Emparentat amb el motiu de la pèrdua de la visió en un ull o en els dos, hi ha també un curiós relat miraculós que sant Vicent reconta en el sermó CXXII, en què un estudiant devot desitja veure la Mare de Déu. Un àngel se li apareix i li explica que, si vol, la podrà veure, però hi quedarà cec, «car huylls que vehen tan excel-lent senyora no deuen veure depuix altres dones». Davant d'aquesta terrible conseqüència, l'estudiant decideix, amb enginy: «No, més val que·m tape la hun huyll, quant ella vindrà, e depuix, encara que sia cech de la hun huyll, depuix veuré'n ab l'altre». L'estudiant ho fa així, però la visió de la Mare de Déu li resulta tan bella que desitja tornar-la a experimentar, ni que siga amb el sacrifici de l'altre ull. Davant d'aquesta mostra de devoció, la Mare de Déu, quan s'hi torna a mostrar, li fa la gràcia de restituir-li la vista als dos ulls (FERRER 1410: IV, 191-192).

2 En el context cultural català, fins ara, disposem de tres valuoses documentacions per a aquest motiu 1331: una a Catalunya i dues a la Catalunya Nord. En el cas de Catalunya, hi ha el relat «Treure's un ull perquè un altre se'n tregui dos, o perquè un altre resti cec», recollit per Amades (1950: 11251126); a la Catalunya Nord, Esteve Caseponce va recopilar a primeries de segle xx sengles versions, en els contes «L'home i el gra de mill» (CASEPONCE 1907: 31-37) i «L'avar i el gelós» (CASEPONCE 1907: 66-72). Resulta curiós que en la completíssima base de dades Rondcat no conste cap versió valenciana d'aquest motiu ATU 1331: senzillament pel fet que no ha estat recopilat en l'obra de cap dels rondallaires catalogats (dels segles XIX, Xx i XxI). L'exemple citat dels Sermons de sant Vicent, que òbviament s'adscriu a aquest ATU 1331, és, per tant —el fet mereix ser subratllat- la primera catalogació del motiu en qüestió dins de l'àmbit cultural valencià. A pesar que el referent en què s'inscriu té ja més de 600 anys d'antiguitat!

REVISTA VALENCIANA DE FILOLOGIA / I I I (20I9) p. 5I-76

JOAN BORJA I SANZ

L'imaginari popular en sant Vicent Ferrer: semblances i exemples en els Sermons vicentins / 57 
envejós no ha bé, ni qui de prop lo té», conclou sentenciosament el predicador, amb un enunciat que, per l'estructura binària i la rima interna, ofereix tot l'aire d'una parèmia popular.

També centrada en la figura d'un monarca just, omnipotent i impietós —que després el predicador, naturalment, proposarà assimilar a la figura de Jesucrist, d'acord amb el propòsit evangelitzador- és la curiosa narració del rei que havia manat construir una ciutat nova i volia poblar-la amb homes d'ascendència elevada i llinatge noble. Dos homes que, en principi, semblen respondre a aquest requisit es proposen acollir-se a la crida, però amb estratègies diferents: l'un, amb unes bones provisions; l'altre, confiant el viatge a la bona sort. Òbviament, el destí d'un prohom i de l'altre seran també desiguals:

Un rei era que havia edificat una ciutat, e no la volia poblar sinó de hòmens de paratge. E foren dos companyons de paratge escuders, e ells, oïda la nova, volgueren anar a la ciutat aquella, e cascú se aparellà ab si terç, ell e lo rossí e lo rapaç, e pren per a messió e no pus. Emperò, lo u no curà de proveir-se de ço que havia mester per a la messió, que dix que havia oït dir que un hom havia trobat un bossot, així que Déu li’n depararia, e ell per ço no curà de proveir-se, confiant que trobaria lo bossot. E lo que portava provisió, passava. E aquell altre, un dia venia una cosa, l'altre dia altra, e donà comiat al rapaç, e puis desisqués del rossí, e com fonc en la ciutat, vel-vos descalç, e mal aparellat, desrobat. E plegats a la ciutat, lo que venia a cavall, dix al senyor: «Per tal raó som venguts». Dix al cavalcant: «Entra, que tu me par que sies hom de paratge», e feu-li donar bon recapte. A l'altre, feu-lo penjar, dient que ribaut devia ésser. Déu vulla que no hi sien molts. (FerRer 1413: II, 162) ${ }^{3}$

Més cruel i feridora encara és la història del rei «appellat Dombezech», que lluny de qualsevol possibilitat d'identificació amb la divinitat, serveix per

3 Sant Vicent fa servir una altra versió d'aquest mateix relat en el sermó XXVI, "In vigilia Sancti Iohannis Babtiste» (FerRer 1410: II, 8-10). Sanchis Guarner (1973: 26-27) fa servir aquesta altra versió del relat del previsor i l'imprevisor per a il-lustrar que «sovint els exemples dels sermons vicentins eren dialogats, alguns gairebé totalment».

REVISTA VALENCIANA DE FILOLOGIA / I I I (20I9) p. 5I-76

JOAN BORJA I SANZ

L'imaginari popular en sant Vicent Ferrer: semblances i exemples en els Sermons vicentins / 58 
a il·lustrar principis morals del tipus «tal faràs tal trobaràs», "allò que sembres colliràs», "qui fa mal, mal acaba», etc.

Era hun rey appellat Dombezech. Era cruel e havia vençut e preses LXX reys, e per la sua glòria feu que·l seu tinell ere alt, e havia tallat les mans a aquells reys, e los peus, e fehia'ls mengar davall la sua taula, e quan lançava lo os entre ells, venia hun ca e barallave's ab los hòmens, e de açò se rehye aquell rey. E veus que hac anar a una batalla (vide ystoria), e dix així: "LXX reges [amputatis manuum ac pedum summitatibus colligebant sub mensa mea ciborum reliquias] sicut feci, ita reddidit mibi Deus». També fo pres e també li tolgueren les mans e.ls peus. Haa! «De culpa tua peccatum tuum acusa» (FERRER 1410: VI, 216).

Aquest «rey appellat Dombezech», de sadisme hipertròfic i punyent, es correspon, evidentment, amb la figura del rei bíblic Adoní-Bèzec que apareix a l'inici del Llibre dels Jutges com a governador de Bèzec, una ciutat cananea al sud de Jerusalem:

Van començar la guerra i el Senyor va posar a les seves mans els cananeus i els perizites: en mataren deu mil a Bèzec. Amb ells hi havia el rei Adoní-Bèzec; van combatre contra ell i derrotaren els cananeus i els perizites. Adoní-Bèzec intentà de fugir, però el van perseguir i capturar, i li tallaren els polzes de les mans i dels peus. Llavors Adoní-Bèzec exclamà:

Setanta reis, amb els polzes de les mans i dels peus tallats, recollien les engrunes que queien de la meva taula. Ara Déu em paga tal com jo havia fet. I se l'endugueren a Jerusalem, on va morir. (Jt 1:4-7)

Comparant la versió que Vicent Ferrer adapta per al seu sermó amb l'original bíblic, trobem un exemple ben il-lustratiu de les facultats retòriques del dominic valencià per a emfasitzar i extremar — d'acord amb una estratègia efectista i popularitzant - els elements del relat que podien resultar més impactants per a un públic predisposat a quedar-ne impressionat: si en el text bíblic la mutilació és només dels dits polzes dels peus i de les mans, en la predicació

REVISTA VALENCIANA DE FILOLOGIA / I I I (20I9) p. 5 I-76

JOAN BORJA I SANZ

L'imaginari popular en sant Vicent Ferrer: semblances i exemples en els Sermons vicentins / 59 
vicentina els reis són representats amb les mans i els peus completament seccionats; si en el Llibre dels Jutges els monarques s'humilien a haver de recollir les engrunes que queien de la taula d'Adoní-Bèzec, en la versió del predicador valencià és la impietat del rei la que els fa «mengar davall la sua taula», amb una poderosa imatge de collita pròpia com a propina truculenta i punyent: l'espectacle dels setanta reis mutilats — amb monyons als peus i als braçosbarallant-se amb un gos ferotge i disputant-s'hi l'os que Adoní-Bèzec els llança per riure i divertir-se.

Tampoc en el rei que apareix en la celebèrrima llegenda de sant Jordi, el drac i la princesa — que sant Vicent Ferrer no deixa d'aprofitar al servei de les seues predicacions- no se suggereix cap identificació amb Déu o amb Jesucrist. En aquest cas, com és natural, serà la figura de sant Jordi, l'heroi i màrtir patró de la cavalleria, la proposada com a model de conducta virtuosa que cal seguir i imitar. Especialment interessant és el tractament d'aquesta figura de sant Jordi en els sermons de Vicent Ferrer si tenim en compte l'enorme popularitat que, en l'època, tenia el corresponent relat hagiogràfic de la Llegenda àuria. I és que, sant Jordi, en temps de Vicent Ferrer, no solament era el patró de la cavalleria, ans també de tots els regnes que integraven la Corona d'Aragó, incloent-hi, per descomptat, el Regne de València.

En el sermó CC, «De sent Jordi», podem documentar una reeixida versió de la coneguda llegenda de sant Jordi —-derrotant el drac i alliberant la donzella- que ben podria funcionar com un relat independent, eixit dels llavis d'un contacontes contemporani. No ens podem estar, pel valor documental i il.lustratiu, de reproduir-lo tot seguit, sense mutilacions:

Ara escoltat: sapiau que lla en aquella terra havia hun lach gran, e havia-y hun gran drach e menjava's moltes persones. E havia ýdoles en aquella terra, e deyen que la ciutat devia ésser devorada per aquell drach, si ja lo rey no li donava sa filla. E veus que.l rey ó hac a fer, e lo dia que ell hi devia portar sa filla, primo ell la ornà bé de aur e de perles, e la vestí molt gentilment, susaixí com si hagués ésser nóvia. E pensat que•l rey plorant li dix: «Ara, ma filla, yo vos havia el cor de dar-vos a hun gran rey per

REVISTA VALENCIANA DE FILOLOGIA / I I I (20I9) p. 5I-76 JOAN BORJA I SANZ

L'imaginari popular en sant Vicent Ferrer: semblances $i$ exemples en els Sermons vicentins / 60 
muller, mas pus que així és, no s’i pot alre fer». E ella respòs: «Mon pare, bé·m plau, car més val que yo soleta peresca, que vos ni la ciutat». E veus que posaren-la prop lo lach, per tal que.l drac la devoràs. E fon ordenació de Déu que sent Jordi passàs allèn, e ell anava's deportan en hun bell cavall tot sols. E així com fo allí, ell veu la donzella bella molt ben ornada e dix-li: «Odà, donzella! Com sou ací tota sola?», e ella respòs-li: «O bon cavaller, anau-vos-ne, sinó morreu ací ab mi!» «E com és açò?» Ella li comptà tot lo fet, així com vos he dit, e sent Jordi dix-li: «Senyora, no hajau paor, que jo us deffendré ab la ajuda de Jesuchrist». E veus que, ells esta[n]t axí parlant, lo drach hoí les p[a]raules e alçà lo cap sobre l'aygua, ab aquell cap fer guardant-los, e quan la donzella lo veu, tremolà fort de paor, axí com aquella que llavors havia a morir. E sent Jordi aconsolà-la dient: «Senyora, no hajau paor, que Jesuchrist nos ajudarà.» E espaxadament ell apartà lo cavall e descavalcà. E lo drach, que veu que aquell se amania per deffendre's, lexà la donzella e corregué a sent Jordi. E sent Jordi, invocant lo nom de Jesús, donà-li una gran lançada, que sus allí romàs mort. E aprés prengué la donzella e molt honradament menà-la al rei. Pensat que-l rey ne hac gran plaer e volia-l'i donar per muller, e sent Jordi no·u vol[1]ch, mas dix-li que la donàs a Jesuchrist. E axí fo, car lo pare e ella e tota la ciutat se bategaren (FERRER 1410: VI, 79).

No és aquesta, tan mateix, l'única versió de la llegenda de sant Jordi que podem trobar en els sermons vicentins. L'efectisme del relat, i la mateixa emotivitat que l'han fet perdurar vivament des de l'edat mitjana fins als nostres dies en l'imaginari compartit i el gust popular, devien oferir un valor inestimable per als propòsits discursius del predicador. I, així, en el sermó corresponent al dia «25 d'abril» de 1413, en els anomenats Semons de Quaresma (numerat com a LII), en podem llegir aquesta altra saborosa versió:

Una singular cosa. En una província prop de la terra de Capadòcia, en Líbia, era una ciutat, e regnava-hi un gran rei, e lo rei no havia sinó una filla, bella e molt gentil; e en aquella ciutat adoraven ídoles. E los dimonis no són contents que la persona faça pocs pecats, mas molts. Com haguessen en la ciutat ofert a l'ídol, e dimoni, de totes coses, venc que el

REVISTA VALENCIANA DE FILOLOGIA / I I I (20I9) p. 5I-76 JOAN BORJA I SANZ

L'imaginari popular en sant Vicent Ferrer: semblances i exemples en els Sermons vicentins / 6I 
dimoni los dix que li oferissen los fills: «immolaverunt filios daemonibus» (David, en lo psalm Cofitemini: Ps, 105, 37). Prop d'aquella ciutat, en un estany d'aigua, havia un gran drac, e adoraven-lo per Déu (Nn, 13) (en Babilònia així mateix adoraven un drac). Lo dimoni donà a entendre que la filla del rei havia d'ésser oferida al drac, e lo rei ipensau, pensau com estava!, e lo poble se apoderava. Lo pare de la donzella, ço és, lo rei, la ornà gentilment, e tramés-la al drac; e la gent, per terrats e per lo mur, mirant. Sent Jordi, per revelació divinal, ell venia armat, e no menava sinó un rapaç, deixant l'altra gent; e ell venc prop del llac, e veu la donzella, e de fet descavalcà e comanà son cavall al rapaç, e acostà's a la donzella. E ella li dix: "Valent cavaller, anats e fugits; no vullats morir, que no em poríeu ajudar». E sent Jordi prenia cor, e ella dix-li que esperava lo drac que isqués, e era llur déu, e havia manament que ella fos vianda sua. Dix sent Jordi: «Jo esper que nostre senyor Déu Jesucrist me’n darà victòria: hajats bon cor». Sent Jordi cavalcà, el lo drac ve contra sent Jordi, e sent Jordi se senyà ab lo senyal de la creu, e dix: «Jesús!», e feríll. Uns dien que caigué mort lo drac, e ell descavalcà e pres la donzella per la mà, e menà-la a son pare. Pensau que la donzella que veu aquell cavaller tan valerós, podeu pensar que la donzella diria al pare: «Pare, jo me tendria per arreada que fos mon marit». Dix lo rei: «Cavaller, jo la’t do per muller, e lo regne meu». E dix sent Jordi: «Dona-la a Jesucrist, que ell l'ha deslliurada, que no jo». E així lo pare e ella, e més de vint mília hòmens de la ciutat, se batejaren. Així, no li anava lo cor a luxúria ne carnalitat. ¡Quants cavallers hi ha, que si la trobassen, dixeren: «Jo us deslliuraré del drac de l'estany, mas venits-ne ab mi, e jo seré lo drac que us devoraré»! (FERRER 1413: II, 190-191).

Aquesta resolució del relat, que fa palesa la tensió amatòria latent entre l'heroi redemptor i la donzella rescatada, delata la convergència existent entre la llegenda de sant Jordi i el motiu rondallístic de l'heroi que venç el drac, allibera la donzella i, al final, s'hi casa. Ens referim, òbviament, al tipus ATU 300, «The Dragon-Slayer». Segons l'esquema argumental d'aquest relat universalment conegut:

REVISTA VALENCIANA DE FILOLOGIA / I I I (20I9) p. 5I-76 JOAN BORJA I SANZ

L'imaginari popular en sant Vicent Ferrer: semblances i exemples en els Sermons vicentins / 62 
A youth [...] comes to a town where people are mourning and learns that once a year a (seven-headed) dragon demands a virgin as a sacrifice. In the current year, the king's daughter has been chosen to be sacrificed, and the king offers her as a prize to her rescuer. The youth goes to the appointed place. [...] the youth overcomes the dragon [...] the dragon-slayer marries the princess (UTHER 2011: I, 174).

Es tracta, per entendre'ns, del motiu de l'heroi, el drac i la serp que en la tradició rondallística valenciana ha quedat conservat en una rondalla com «La Mare dels Peixos», recollida per Enric Valor (1975: 56-78); "La flor del Jerigó», recollida per Josep Bataller (2001: 24); «La serp de set caps», de Diéguez, Llinares, Llorca i Montiel (1999: 79-81); «La serp de set caps» i «Els tres gossos», de Rosabel i Mari Roig Vila (1999: 167-170 i 183-186); «La serp de set caps», de Torres i Giménez (1993: 33-37) o "Els dos germans bessons», de Jordi Raül Verdú (2014: 41-49).

Al capdavall, el drac del relat de sant Jordi en la Llegenda àuria simbolitza, en essència, la força del mal. Com l'heroi de la rondalla, sant Jordi no és sinó la tipificació de l'heroi virtuós que aconsegueix véncer l'amenaça de la fatalitat. Per dir-ho així, una herència cristiana del mite grec de Perseu, Andròmeda i Cetus: de la mateixa manera que aquest últim mite ben es podria entendre — si encara volguérem retrocedir més arrere en la successió de tradicions cultural-com una herència del mite egipci del déu Horus. I val a dir que, sense eixir de les Rondalles valencianes de Valor — per tornar a referències més immediates i concretes-, el motiu de l'heroi que venç una serp (bèstia homologable al drac en aquest univers literari) també pot ser documentat en «El gegant del Romaní» (ATU 302), «Esclafamuntanyes» (ATU 301), «El castell d'entorn i no entorn» (ATU 425B), «Don Joan de la Panarra» (ATU 1640) i «El patge saguntí» (ATU 514**).

Més encara: el motiu etnopoètic del sant Jordi Matamoros d'Alcoi també es podria entendre i interpretar, perfectament — d'acord amb aquesta gramàtica de la fantasia - com una adaptació d'aquest motiu recurrent de l'heroi que venç el mal: només hi caldria tenir en compte, en el moment de sospesar-ne la hipòtesi, les necessitats propagandístiques derivades de la severa

REVISTA VALENCIANA DE FILOLOGIA / I I I (20I9) p. 5 I-76 JOAN BORJA I SANZ

L'imaginari popular en sant Vicent Ferrer: semblances $i$ exemples en els Sermons vicentins / 63 
derrota que els sarraïns van imposar a les tropes cristianes de Jaume I en la coneguda batalla d'Alcoi de 1276 .

Siga com vulga, ja al marge dels relats protagonitzats per cavallers, senyors feudals i monarques, un altre tipus de relats populars medievals presents en els sermons de Vicent Ferrer és el que protagonitzen els animals amb atributs humans. A la manera de les faules o les «rondalles d'animals» (que en l'índex internacional dels contes folklòrics són catalogats amb tipus ATU entre 1 i 299), tenen per protagonistes uns animals que, més evidentment o més subtilment personificats, són proposats en qualsevol cas per a la tipificació i la caracterització d'actituds, conductes i valors humans. Pot servir com a primer exemple el de la rabosa que es fa la morta al mig d'un camí. Es tracta d'una interessant narració que trobem inserida al bell mig del sermó LXXXVII:

Sabeu que la rabosa és molt falsa, e sabeu com esdevench-se una vegada que hun pescador portave peix en una cistella, e la rabosa, per haver lo peix, gità's com a morta en lo camí per hon devie passar lo pescador, e aquest donà-li ab lo peu e ella estigué segura, e lexà-la estar, e té son camí; e la rabosa levà's, e espaxadament insqué-li a davant, e gità's com a morta en lo camí; e·l pescador donà-li ab lo peu, e ella està segura; e aquest esmaginà en si mateix que serie bo que tornàs a la primera rabosa, e que les se'n portàs abdues; $\mathrm{e}$ lexà la cistella aquí, per tornar a la primera rabosa (e tot ere una rabosa); e axí com ell tornà a la primera, aquesta mengà's lo peix, e va-sse'n, e axí lo pescador ni hagué les dues raboses ni.l peix (FerRER 1410: II, 276-277).

Es tracta d'un relat que, igual com s'esdevenia amb la llegenda de sant Jordi, també apareix repetit en més d'un sermó. Fet i fet, en el LXXIX, corresponent a la «Fferia $\mathrm{III}^{\mathrm{a}} »$, podem observar-ne una referència coincident:

La rabosa pose's e.l camí com a morta, e lo pescador haurà'n trobada una altra, e serà aquella matexa, e dirà: "Més val que torno a l'altra», e lexarà aquí lo peix, e ella mengar-lo s'ha e fugirà, e lo pescador no haurà peix ne raboses. La dona dirà al prevere: "Yo só pobra e faré vostres plaers, si·m donau de vòstron argent»; e quan lo haurà desfet, metrà-li escusa,

REVISTA VALENCIANA DE FILOLOGIA / I I I (20I9) p. 5I-76

JOAN BORJA I SANZ

L'imaginari popular en sant Vicent Ferrer: semblances i exemples en els Sermons vicentins / 64 
que son marit ó ha sentit, e.l mesquí de prevere no haurà dona ne argent (FERRER 1410: III, 196).

Resulta senzillament fascinant constatar que aquest reiterat motiu de la rabosa fent-se passar per morta per enganyar el pescador no és sinó una molt antiga i curiosa variant del tipus ATU 1, «The Theft of Fish»:

A fox (hare, rabbit, coyote, jackal) lies in the road pretending to be dead. A fisherman throws him on his wagon which is full of fish (cheese, butter, meat, bread, money). The fox throws the fish out of the wagon and jumps down after them.

A wolf (bear, fox, coyote, hiena) tries to imitate this and pretends to be dead, too. The fisherman catches him and beats him.

In some variants one animal (rabbit, fox) pretends to be dead in order to distract a man who is carryng a basquet of food. Another animal (fox, wolf) teals the basket. Or an animal makes a hole in the basket so that the contents fall out. (UTHER: 2011, I, 16)

Es tracta d'un motiu rondallístic ben conegut en temps contemporanis dins l'àmbit cultural català gràcies a un parell de recopilacions: "Compare llop i comare guilla robant formatges», de Joan Amades (1950: 802) i «La guineu i el llop, fent el mort», de Bertran i Bros (1989: 201-202). Tanmateix, en cap dels reculls contemporanis de rondallística valenciana no apareix aquest tipus de conte, per la qual cosa aquests exemples dels sermons de sant Vicent Ferrer tenen el valor de ser ara com ara la primera — i única— - versió catalogada respecte d'aquest motiu ATU 1 en el context valencià. ${ }^{4}$ De més a més, es produeix la interessant

4 Aquesta documentació de l'ATU 1 en els sermons de sant Vicent no apareix recollida en la base de dades RondCat (rondcat.arxiudefolklore.cat) —òbviament, per raó del corpus bibliogràłic que s’hi considera, restringit als segles XIX i Xx. Per això, actualment (novembre de 2018), continua sense constar cap referència valenciana per a aquest ATU 1. Els sermons de sant Vicent tenen, per tant, el valor de ser, ara com ara, el primer testimoni identificat d'aquest motiu rondallístic en la tradició oral valenciana. No deixa de ser curiós que, en la rondallística valenciana, aquesta primera catalogació del tipus ATU 1 que ací fem siga en una font de més de 600 anys d'antiguitat!

REVISTA VALENCIANA DE FILOLOGIA / I I I (20I9) p. 5I-76

JOAN BORJA I SANZ

L'imaginari popular en sant Vicent Ferrer: semblances i exemples en els Sermons vicentins / 65 
circumstància que, mentre les versions recollides per Amades i Bertran i Bros apunten al motiu de la rabosa i el llop robant formatges, la de sant Vicent Ferrer, per contra, recrea el motiu originàriament previst en The Types of International Folktales: el del pescador i el peix (en comptes del carreter i els formatges).

També una rabosa amb capacitat de parlar serveix per a vivificar el discurs en aquest mateix sermó LXXIX, una mica abans:

E pren-los-ne axí com feu una vegada a la rabosa: ella vench a hun corral on havie bestiar, e lo pastor sentí-la e entreobrí les portes e dix: "Qui és axò?» Dix ella: «Yo so ca». Diu lo pastor: «Vos podeu dir que sou ca, mas vos rabosa me semblau» (FerRer 1410: III, 194-195).

Cans de veritat són —aquests sí- els animals personificats que protagonitzen un nou exemple, en què es reconta la situació creada quan els gossos, en assemblea, decideixen atacar i matar tots els llops. La curiosa i raonada resolució de la breu trama narrativa no deixa de suggerir l'assumpció d'una actitud que, incardinada dins de paràmetres pacifistes i de convivència en la diversitat, ben bé s'adiu amb les funcions de pacificador que, en termes biogràfics, el mateix sant va haver d'assumir en alguns conflictes humans: ${ }^{5}$

E ací vos diré una paraula dels cans. Sapiau que diu que una vegada tots los cans se aplegaren e tingueren consell que anassen a matar tots los lops, que mal ere, que molt de mal fahyen. E axí o feren. Los lops saberen-ho e aplegaren-se tots, e los cans vingueren, e ans que no s'aplegassen, hun lop antich anà a parlament als cans e dix-los: "Vosaltres, senyors, sou venguts ací per batallar ab nosaltres, e si nosaltres vencem, sere[u] morts, tots, e mala per a vosaltres; o si venceu vosaltres, mala per a nosaltres e per a vosaltres; car ara les gens vos governen per amor de nosaltres, e des que hajau mort a nosaltres, no us governaran, e així us morreu de fam. E axí consellar-vos hia que us ne tornàsseu». E tots

5 Podeu veure exemples de translació a l'imaginari popular d'aquest prestigi de sant Vicent com a mediador i pacificador en l'apartat «4.5.2 Reconciliacions».

REVISTA VALENCIANA DE FILOLOGIA / I I I (20I9) p. 5I-76

JOAN BORJA I SANZ

L'imaginari popular en sant Vicent Ferrer: semblances i exemples en els Sermons vicentins / 66 
acordaren que més valia, e almenys no morrien de fam, e los lops no prengueren mal (FERRER 1410: VI, 51).

Sempre dins d'aquestes històries d'animals, el sermó CXXI ofereix també un original exemple en què el suposat costum dels cérvols, de trencar-se les banyes i mudar la pell en fer-se vells, serveix com a il-lustració doctrinària:

Dien los naturals que lo cervo, quant és vell, los corns li’s tornen pesats e grans, e per ço, com és vell, no·ls pot adur, e té lo cuyro gros e no pot així córrer. Mas ell què fa? Veus que menga de una erba que és molt fort, que si hom ne menjava, morria. E quan l'a menjada, ell crema tot e va-sse'n a una font que brulle frescha, e banye's allí, e ab la ardor de dins e ab la fredor de fora, les banes li cahen, e la pell li’s muda, e així ell torna jove (FERRER 1410: IV, 187).

A aquest mateix motiu de la vida renovellada apunta el cèlebre mite de l'au fènix, especialment popular en el cristianisme primitiu, que el nostre predicador tampoc deixa d'aprofitar en les seues predicacions:

Dien los naturals que en lo món que no·y ha sinó hun fènix, hun ocell que s'appelle fènix. E quan ha viscut $\mathrm{D}$ anys, diu que fa hun niu de buscalles; e quant ell coneix que les buscalles són ben caldes, lleve's sobre elles, e ab les ales bufe-y tant, fins que s'i pren foch, e quan són ben enceses, ell se met dins les buscalles e creme's allí tot, sinó lo cor; e hix-ne un verme de tot, e puix torna altre fènix, e així se renovella (FERRER 1410: IV, 188).

Molt semblant a aquestes imatges del reviscolament del cérvol i de l'etern renovellament de l'au fènix és l'exemple de l'àguila que, en fer-se vella, colpeja el bec ganxut contra una pedra per trencar-lo i rejovenir-se:

E havem-ne exemple en natura: que la àguila, quan és vella, diu que lo bech li's torna com a ganxo e no pot pendre la vianda ni pot menjar, e per ço torne magra e té les les plomaces grans, que tota torne quasi ploma,

REVISTA VALENCIANA DE FILOLOGIA / I I I (20I9) p. 5I-76

JOAN BORJA I SANZ

L'imaginari popular en sant Vicent Ferrer: semblances $i$ exemples en els Sermons vicentins / 67 
Mas veus que fa ella: se'n va a una pedra e fir fort allí ab lo bech fins que·s trenqua; e puix egual·la'l, e llavors va a caça e tarte's, e axí torne gorda e jove (FERRER 1410: IV, 186).

Precisament sobre aquest mateix motiu de la vellesa tracta un nou exemple animalístic, relatiu a la cigonya i a les atencions que els fills li solen dispensar quan, ja ella major, la porten dins del riu i l'assisteixen. ${ }^{6}$ Aquest exemple, curiosament, és enllaçat, en el corresponent sermó, ${ }^{7}$ amb un altre exemple colpidor, protagonitzat ja per personatges humans, en què la caritat i l'enginy d'una filla aconsegueix salvar la vida de la mare, ja vella, que ha estat sentenciada a morir de fam dins d'una presó:

Los romans adoraven imatges de bèsties e no d'ocells ni de la cegonya, perquè a la vellea los fills la meten en lo niu e porten-li a menjar, e quan és dura de ventre, lo fill e filla van a la mar e umplen-se la boca de aigua salada, e meten lo bec en aquella partida, e donen-li cristiri e ajuda (ara, los hòmens, si han pare e mare velles, absit); e per esta raó, los romans no feien ídola de cegonya.

Exemple. En una ciutat era una dona, e per un gran crim fonc sentenciada que morís de fam: pens que devia ésser alguna honrada dona. La dona havia una filla, e la filla criava sa criatura, e sabent que era sentenciada sa mare, així la filla feia alletar son fill, e ella conservava la llet per a sa mare. E hac gràcia que hi entràs a visitar sens vianda, e així, conservant la llet, e com era entrada en la presó, dava a mamar a sa mare e buidava-li les mamelles, així dos vegades lo dia, hora de dinar e al vespre. Així la sostenc molts dies, e lo jutge deia: «Com se pot fer que no sia morta?» Lo

6 No fora del tot desafortunat suggerir una relació entre aquest motiu medieval i un parell de relats populars documentats en l'àmbit valencià en la primera meitat del segle xx: «Sap més que li han ensenyat», recollit per Francesc Martínez i Martínez a Altea (1912: 143-145), i «No ens enganyaras, còrb, que tens el pic negre», recopilat a Bolulla per Sara Llorens (BorJA 2016: 69-70). En un cas i en l'altre, la narració tracta sobre un corb vell i sense plomes, que ja no pot buscar menjar ni fugir dels perills pels seus mitjans, i decideix posar-se dins d'un niu fent-se passar per una cria de corb.

7 «XXV. Fèria IV després de la terça domínica de Quaresma (29 de març)» (Ferrer I4I3: II, I3-I 8).

REVISTA VALENCIANA DE FILOLOGIA / I I I (20I9) p. 5I-76

JOAN BORJA I SANZ

L'imaginari popular en sant Vicent Ferrer: semblances i exemples en els Sermons vicentins / 68 
jutge dix: "No pot ésser», e lo jutge ho volc veure, e veu que la vella mamava. Plagué-li tant esta pietat, que delliurà la mare. Esta era bona filla. «Honora patrem e genitus matris non obliviscaris» (Ecli, 7, 29). «Filii, obedite parentibus in Domino; ho justum est, quod est mandatum legis» (Ef, 6, 1): «Obeïts-los, no contra Déu, mas que sia plasent a Déu, e nostre senyor Déu te guardarà de tots perills» (Ferrer 1413: II, 16).

Més generosa i pietosa encara és l'ajuda dispensada a un altre presoner sentenciat a mort en una altra de les semblances recontades per Vicent Ferrer. Es tracta d'una prova d'amistat extrema, en què l'oferiment d'un amic a ser penjat per comptes de l'amic que ha estat condemnat a la forca va molt més enllà de la pura declaració d'intencions:

Una semblança. Eren dos hòmens, grans amics, e lo u feu un gran furt, e fon sentenciat a la forca, e estava en la presó. E l'altre amic vestís de dol e venc al carceller, e recaptà gràcia del senyor e dels jutge que entràs en la presó per aquell. Lo companyó li diu: «Tant te ame, que vull ésser penjat per tu», e despullà's les vestidures, mudant-les-se, e penjaren aquell bon amic (FERrer 1413: II, 91). ${ }^{8}$

Per la seua part, també el domini de la meteorologia que molts relats populars actuals atribueixen al sant té un curiós correlat en el miracle de sant Pere Màrtir i el núvol, que el mateix sant Vicent conta en un dels seus sermons:

Sapiau que hun dia, axí com [sent Pere Màrtir] preÿcava a molta gent fora la ciutat, veus que fahya gran sol, e la gent sostenia gran calor per lo sermó, e ell hac-ne pietat e pregà a Jesuchrist: «Senyor, prech-vos que

8 Aquest motiu de l'home que substitueix un amic condemnat a mort i dona la vida per ell apareix també en el sermó CLVII: "sapiau que una vegada fo hun ladre, e fo pres e sentenciat a mort; e ell havie hun amich, e aquell hac-ne compassió, dient: "Oo, mon amich que tant amava, serà pengat demà!". E què feu? Anà-sse'n a la presó e pregà al carceller que·l leixàs entrar a veure son companyó; e leixà'l entrar e dix-li: "Sàpies que demà has a ésser pengat. E axí yo te diré com o faràs. Da'm les tues robes e tin les mies, e ves-te'n, e yo seré pengat per tu”. E axí fo» (FERrer 1410: V, 111).

REVISTA VALENCIANA DE FILOLOGIA / I I I (20I9) p. 5I-76

JOAN BORJA I SANZ

L'imaginari popular en sant Vicent Ferrer: semblances i exemples en els Sermons vicentins / 69 
vullau trametre una núvol que·ls cobra». E veus que subito hac allí una núvol. e la gent hac-ne gran plaer (Ferrer 1410: VI, 91).

Especialment suggeridora és la semblança d'aquest miracle de sant Pere Màrtir protegint la multitud de feligresos que acudia a les seues predicacions, amb el d'aquest altre relat popular que mossén Alcover recull a Son Gual de Valldemosa, atribuït precisament al predicador valencià:

Va esser damunt un pujolet a on encara hi ha una caseta que li diuen de sant Vicenç.

Mentres predicava, se posa a ploure. N'hi hagué que fugiren i se'n dugueren una bona banyadura, que els arrià fins a sa pell. Es qui no es mogueren i escoltaren es sermó no es banyaren gens, i tornaren an es poble tots xalests (Alcover V: 120-121).

També un miracle vicentí documentat contemporàniament al municipi valencià de Teulada, «El calbot del moro", ${ }^{9}$ sembla tindre similitud amb un miracle reportat per Vicent Ferrer en un dels seus sermons de Quaresma. Ens referim al miracle següent, de la bufetada en l'ombra:

Un miracle. Un religiós havia tengut son orde: tant de bé havia fet, e en esta santedat estec molt de temps, e ell llegia com han alguns sentiments de Déu persones devotes, e ell no n'havia. Un dia, aprés matines, ell romàs en la eclésia, e començà a al·legar mal: «iSenyor beneït! Oig dir que persones que us serveixen, han de grans delectacions en vos, Senyor. Si jo hagués servit un tirant, mostrara'm algun senyal de amor». Subito, venc una ombra, e donà-li tan gran bufetada, que el gità en terra, e dix-li que no n'hauria d'aquella dolçor fins que es menyspreàs tant com a fang (FERRER 1413: II, 135).

Fins i tot, l'inquietant motiu del canibalisme que protagonitza el famós miracle del xiquet esquarterat i guisat a Morella (vegeu Borja 2014: 345-347)

9 Vegeu Borja (2014: 341).

REVISTA VALENCIANA DE FILOLOGIA / I I I (20I9) p. 5I-76 JOAN BORJA I SANZ L'imaginari popular en sant Vicent Ferrer: semblances $i$ exemples en els Sermons vicentins / 70 
—relacionat amb el tipus ATU 720, «My Mother Slew Me; My Father Ate Me», i amb el conegudíssim conte de «Peret i Marieta»—, ${ }^{10}$ sembla tindre un curiós referent en la semblança del pare que, sense saber-ho, menja la carn del seu fill. Ens referim, en concret, a aquest feridor passatge del sermó LXXII: ${ }^{11}$

E dir-vos una semblança. Si hu de vosaltres covidave hun hom a dinar, amich seu, e quan vingués al dinar, que li donàs a mengar lo fill de aquell, e aprés mengar, que li digués: «Ha-us sabut bo?». «Hoc, certes». "Donchs, vostre fill vos haveu mengat». Digues, què farie aquell? Axí és de aquell qui fa l'almoyna, capellania o altra obra de usures (FERRER 1410: III, 137).

Molt més directa i evident és com es reporta la incapacitat del dimoni per a aconseguir informació fidedigna sobre l'evolució dels esdeveniments en el Compromís de Casp. En aquest cas, el relat del predicador en un dels sermons de la Quaresma de l'any immediatament posterior al d'aquella reunió de notables en què el mateix Vicent Ferrer va ser decisiu per a l'entronització de Ferran d'Antequera com a nou rei de la Corona d'Aragó, difereix molt poc de la llegenda "El dimoni a distància» (Borja: 327-328). Fet i fet, resulta més que probable que l'origen —i la propagació- d'aquest motiu s'haguera de trobar en els mateixos sermons del frare valencià.

¿Pensats que los diables sàpien totes coses? No. Així fon en lo castell de Casp. Molts invocadors de diables hic havia, e deien al diable: "¿Qui han declarat que sia rei?» E deia-li falsies. «E ja han conclús, ¿̇e dius-me falsies?» Dix lo diable: «Sàpies que de tres llegües no s'hi pot acostar nengun diable». Sí, el diable no sap, com nostre senyor Déu los encega per llur pecat; mas han vergonya de dir-ho, e dien a vegades falsies. Així,

10 Vegeu versions valencianes d'aquest conte, per exemple, en Diéguez, Llinares, Llorca i Montiel (1999: 13-16), Guardiola i Beltran (2005: 141-142), Limorti i Quintana (1998: 38-39), Micó (2009: 109-110), Roig i Roig (1999: 135) i Verdú (2006: 55-58).

11 Aquest passatge, igualment, evoca el motiu de la llegenda del cor menjat atribuïda a Guillem de Cabestany: un motiu que no deixa de ser coincident amb el d' "El Manco Calderon, bandoler de Cocentaina» (vegeu BorJA 2005: 181-183).

REVISTA VALENCIANA DE FILOLOGIA / I I I (20I9) p. 5 I-76

JOAN BORJA I SANZ

L'imaginari popular en sant Vicent Ferrer: semblances i exemples en els Sermons vicentins / 7 I 
no vullats dar creença a diables: esquivats-ho fort. E per ço Jesucrist no volia que diguessen res los dimonis, e així, en esta ciutat, hi ha proveït contra los fetillers e adevins: mester és que es serve (FERRER 1413: II, 23).

A la manera de les facècies de beneits, ${ }^{12}$ sant Vicent il-lustra una de les seues predicacions amb la història d'un llaurador que vol aprofitar l'oferiment d'un rei que decideix convidar a dinar tots els qui s'hi presenten a sa casa amb les mans llavades. Aquell bon home, en efecte, es llava ben llavades les mans i la cara abans d'acudir al convit, d'acord amb l'exigència reial. No obstant això, entre el moment de llavar-se i el de presentar-se a les dependències del monarca, decideix aprofitar el temps d'una manera no massa coherent amb les expectatives higienistes del monarca:

Si huy havia ací hun rey, e per la sua magnificència volie covidar a tots quants són en aquesta vila, dient axí: "Tots quants vinguen demà a dinar ab les mans lavades, yo li daré a dinar». E quan ve en l'endemà, veus que diu hun laurador: «O, a dinar m'e anar a casa del rey; donchs lavar m'e les mans e la cara». Açò és bo. E, quan açò ha fet, veus que encara no és hora de anar a dinar, e diu: «Donques, iré-me'n al ort», e va-sse'n lla, e escampe fems per aquell ort, a així, manegant-lo, sulle-se'n totes les mans; e quan la hora de dinar ve, la trompeta toque. «E ja toquen! Ire'm a dinar»; a va's axí a casa del rey ab les mans sullades. E axí, com lo rey lo veu venir axí sútzeu, diu-li: «E com vens axí sútzeu?» «Senyor, ¿e no digués vos axí, que qui vindria ací a dinar ab les mans llavades, que vos li daríeu a dinar?». «Sí». «E yo ja·m laví huy per lo matí bé les mans e la cara». «Hoc, mas sútzeu és ara». Ara bé podeu pensar que a aquell aytal què li devie fer lo rey. ¡O, que·l fartàs de bastonades! (Ferrer 1410: I, 100-101).

Igualment extreta d'una rondalla costumista o picardiosa sembla la paràbola de l'home pobre que rep l'ajuda d'un home ric, que li dona tota una

12 En referim ací a les «Stories about a Fool», catalogades en l'índex internacional entre els tipus 1200-1349 (UTHER 2011: II, 72-151).

REVISTA VALENCIANA DE FILOLOGIA / I I I (20I9) p. 5 I-76

JOAN BORJA I SANZ

L'imaginari popular en sant Vicent Ferrer: semblances $i$ exemples en els Sermons vicentins / 72 
masia amb l'única condició que cada dia li haurà de portar, simbòlicament, set ous. Al principi, el beneficiat complia aquest pagament dels set ous. Però al cap de poc temps comença a dur a terme una inesperada pràctica per a defraudar que el delata en tant que home desagraït, que no mereix l'usdefruit d'aquella masia:

Sapiau que una vegada ere hun hom pobre, e havie muller e fills, e no havie que·ls donàs. E hun rich hom, vehent açò, hagué'n pietat e donà-li una masia ab ses possessions, dient-li: «Tu és pobre, no tens de què viure, yo te don açò, que estigues ací, ab què pugues viure; e tot ço que n'hauràs, sí és teu. Emperò, en senyal de senyoria, daràs a i quiscun dia set ous.» «Plau-me», dix aquell, e prengué la possessió e dave-li los set ous cascun dia. E per avant enugà-sse'n, e dix: «E què? Cada dia li hauré a dar set ous? Yo sé què faré: trauré'n lo rovell, e lo blanch romandrà dins, e darlos-li he així.»E axí ho feu, en tant que hun dia lo senyor li dix: «Porta’m ous, que puxa menjar». Portà-li'n, e n·y trobà res sinó la cosqua. Lo senyor se aïrà contra aquell: «Ho, hoo, e axí o ha fet aquell traÿdor?» Ell li tol la heretat, e depuix morie de fam (Ferrer 1410: IV, 94-95).

Fins i tot, els sermons vicentins ens permeten de documentar cançons populars vinculades a una mena d'adoració pagana - mes o menys innocent i infantil— de la màgia de la lluna, que Vicent Ferrer tampoc no s'estarà de denunciar:

«Ydolatri» són aquells qui adoren lo sol. ¿Ha·y degú ací que quan hix lo sol, que li digue: «Ben sies vengut; sol, fes-nos aquesta gràcia; que hajam prou pa, prou vi e prou fruyta»? O, ydòlatre! ¿E al sol fas gràcies? A Déu, a Déu les fes, que·l sol no ha ànima, ne rahó, que així és com una pedra. E semblantment a la luna, quan és nova, que dien: «La luna de ma padrina / que-m farà cot i camisa / de cendat e de morat, / que Déu me cobre de bon fat / a la porta del mercat». Burles són: la luna una pedra és, e no ha ànima, e los pintors que la pinten ab cara, no saben què̀s fan (FerReR 1410: II, 147-148).

REVISTA VALENCIANA DE FILOLOGIA / I I I (20I9) p. 5I-76

JOAN BORJA I SANZ

L'imaginari popular en sant Vicent Ferrer: semblances $i$ exemples en els Sermons vicentins / 73 


\section{Conclusions}

El cicle llegendari vicentí, amb una enorme quantitat de relats tradicionals documentables, és, en els temps moderns, un dels més productius en l'imaginari valencià popular. Del riquíssim i diversíssim corpus dels miracles del pare Vicent es desprén una curiosíssima imatge del sant que respon, més que no a l'estricta biografia del predicador apocalíptic, a un tarannà curiosament alegre, sensual, festiu, humorístic, extremat, palpitant, jocós i joiós, perfectament coherent amb els tòpics tradicionalment atribuïts al poble valencià. No debades, la figura d'aquest influent dominic de fama universal, que la història va canonitzar com el primer sant del Regne de València després de la conquesta del rei Jaume I, sembla haver atret $\mathrm{i}$ haver aglutinat la personalitat, la sensibilitat i l'emotivitat —els gustos, les preferències, les inclinacions, les dèries i les quimeres- d'alguns elements identitaris potser essencials en l'etnohistòria valenciana. Per això, l'embolcall llegendari que s'hi ha anat construint sovint ha estat considerat com una mena d'espill on, a fi de comptes, es projectaria $\mathrm{i}$ es reflectiria la personalitat col-lectiva dels valencians, diacrònicament forjada.

Tanmateix, més enllà del sant Vicent protagonista de llegendes, rondalles i escenificacions teatrals tradicionals, Vicent Ferrer ofereix, objectivament, un notabilíssim interés etnopoètic — també- pels relats, els motius, les creences $\mathrm{i}$ les imatges populars que estratègicament incorpora als seus sermons com a exemples o semblances. Tal com hem tingut oportunitat de comprovar, l'anàlisi d'aquests elements manllevats a la literatura popular valenciana (i universal) del segle XV no solament aporta llum sobre les tècniques comunicatives i les estratègies discursives de la predicació vicentina, sinó també sobre aspectes concrets -interessantíssims - del patrimoni etnopoètic valencià. Cal subratllar, en aquest sentit, que algunes narracions internacionalment indexades, que mai abans no havien estat catalogades i reconegudes com a tipus ATU dins de l'àmbit cultural valencià, poden ser efectivament documentades en els Sermons de sant Vicent com a relats inserits en el discurs religiós — amb finalitat moralitzant, il-lustrativa o simplement amenitzadora-. Aquest és el cas, com hem pogut comprovar, del tipus ATU 1331 («The Covetous and the Envious»), i

REVISTA VALENCIANA DE FILOLOGIA / I I I (20I9) p. 5I-76 JOAN BORJA I SANZ

L'imaginari popular en sant Vicent Ferrer: semblances $i$ exemples en els Sermons vicentins / 74 
també del tipus ATU 1 ( «The Theft of Fish»), que podien semblar inexistents en la tradició rondallística valenciana quan, en realitat, es tracta de motius perfectament coneguts i documentats en aquesta tradició des de fa més de sis segles.

El fet, als ulls dels folkloristes valencians, ben bé mereixeria ser estimat i valorat com un prodigi més del sant —aquesta vegada ben concret, real i demostrable-, en el sis-cents aniversari del seu traspàs: un prodigi que, al nostre parer, contribueix a fer, també des de perspectives etnopoètiques, la seua figura encara més interessant, completa i suggeridora.

\section{Bibliografia}

Alcover, Antoni Maria (1936-1972) Rondaies mallorquines d'en Jordi des Recó, Palma, Moll, 24 vols.

Amades, Joan (1950) Rondallística, Barcelona Selecta.

BATAller, Josep (2001) Rondalles de les comarques centrals valencianes, Ontinyent, Caixa d'Estalvis d'Ontinyent.

Bertran i Bros, Pau (1989) El rondallari català, Barcelona, Alta Fulla.

BorJa, Joan (2005) Llegendes del sud, Picanya, Edicions del Bullent.

- (2014) «Sant Vicent Ferrer en l'imaginari popular valencià: una aproximació etnopoètica al cicle narratiu dels miracles vicentins», Ricardo da Costa i Bento Silva Santos, (org.), Mirabilia Journal, núm. 19 (juny-desembre de 2014), pp. 295-350.

- (2016) Les llegendes secretes de Sara Llorens, Llegendes alacantines, Alacant, Universitat d'Alacant. [Inclou l'edició de l'original manuscrit de Sara Llorens Llegendes alacantines (1929), conservat en les carpetes B-156 i C-274 de l'arxiu de l'Obra del Cançoner Popular de Catalunya].

Diéguez, Maria Àngels; Llinares, Maria; Llorca, Francesc-Xavier; Montiel, Rosa (1999) Rondalles de la Marina, Altea, Caixaltea-APA de l'IB Altea.

CASEPOnCE, Esteve (1907) Contes vallespirenchs replegats per En Mir y Nontoquis. Perpinyà.

Ferrer, Vicent (1410) Sermons [Les citacions corresponen a l'edició d' «Els Nostres Clàssics», Editorial Barcino, Barcelona: els dos primers volums, a cura de Josep Sanchis Sivera; i els quatre següents, a cura de Gret Schib].

- (1413) Sermons de Quaresma [Les citacions corresponen a l'edició d'Albatros, València, 1973. Aquesta edició segueix el text publicat per Josep Sanchis Sivera en Quaresma de sant Vicent Ferrer predicada a València l'any 1413 (Barcelona, Institució Patxot, 1927), amb modernització ortogràfica].

REVISTA VALENCIANA DE FILOLOGIA / I I I (20I9) p. 5I-76

JOAN BORJA I SANZ

L'imaginari popular en sant Vicent Ferrer: semblances $i$ exemples en els Sermons vicentins / 75 
Guardiola, Maria Isabel; Beltran, Vicent (2005) Bolulla la caramulla. Cultura popular i llengua d'un poble de la Marina, Alacant: Institut Alacantí de Cultura Juan Gil-Albert.

Limorti, Ester: Quintana, Artur (1998) El Carxe: Recull de literatura popular valenciana de Múrcia, Alacant, Institut de Cultura Joan Gil-Albert.

Martínez i Martínez, Francesc (1912) Còses de la meua tèrra (La Marina). Primera tanda, València, Manuel Pau. [Hi ha edicions facsímils de 1987 (Altea: Aitana Editorial) i 2012 (Alacant: Institut Alacantí de Cultura Juan Gil-Albert)]

Micó i Navarro, Joan Antoni (2009) Bèlgida. Etnologia i rondalles, València, Denes.

Roig Vila, Rosabel; Roig Vila, Mari (1999) Contes $i$ jocs populars de les valls de Guadalest $i$ de l'Algar, Alacant, Institut de Cultura Juan Gil-Albert.

Sanchis Guarner, Manuel (1973) «Estudi preliminar», dins Vicent Ferrer, Sermons de Quaresma, València, Albatros, pp. 7-38.

Schib, Gret (1975) «Advertiment» a l'edició de Vicent Ferrer, Sermons, vol. III, Barcelona, Barcino.

Torres, Lleonard; Jiménez, Llorenç (1993) Rondalles de la Ribera, València, Camacuc.

UtHer, Hans-Jörg (2011) The Types of International Folktales. A classification and Bibliography, Hèlsinki, Suomalainen Tiedeakatemia, 3 vols.

VALOR, Enric (1975) Obra literària completa, vol. I, València, Gorg.

Verdú, Jordi Raül (2006) Una nit prop del foc, Alcoi, Marfil.

- (2014) Això era una volta..., Catarroja, Perifèric Edicions.

REVISTA VALENCIANA DE FILOLOGIA / I I I (20I9) p. 5I-76

JOAN BORJA I SANZ

L'imaginari popular en sant Vicent Ferrer: semblances i exemples en els Sermons vicentins / 76 